\title{
Optical coherent technologies in next generation access networks
}

Katsumi Iwatsuki, Katsutoshi Tsukamoto

Katsumi Iwatsuki, Katsutoshi Tsukamoto, "Optical coherent technologies in next generation access networks," Proc. SPIE 8282, Broadband Access Communication Technologies VI, 828202 (24 January 2012); doi: 10.1117/12.907499

SPIE. Event: SPIE OPTO, 2012, San Francisco, California, United States 


\title{
Optical coherent technologies in next generation access networks
}

\author{
Katsumi Iwatsuki* \\ NTT Service Integration Laboratories, NTT Corporation, 9-11, Midori-cho, 3-Chome, \\ Musashino-Shi, Tokyo 180-8585 Japan \\ Katsutoshi Tsukamoto \\ Graduate School of Engineering, Osaka University, 2-1, Yamada-oka, Suita-shi, Osaka, 565-0871, \\ Japan
}

\begin{abstract}
This paper reviews optical coherent technologies in next generation access networks with the use of radio over fiber (RoF), which offer key enabling technologies of wired and wireless integrated and/or converged broadband access networks to accommodate rapidly widespread cloud computing services. We describe technical issues on conventional RoF based on subcarrier modulation (SCM) and their countermeasures. Two examples of RoF access networks with optical coherent technologies to solve the technical issues are introduced; a video distribution system with FM conversion and wired and wireless integrated wide-area access network with photonic up- and down-conversion.
\end{abstract}

Keywords: Optical coherent technology, Radio over Fiber (RoF), Wavelength division multiplexing (WDM), Passive optical network (PON), WDM-PON,

\section{INTRODUCTION}

Figure 1 shows the transmission speeds of core and access networks over time. The transmission speed of optical access has increased by around 100 times in the last decade. In order to accommodate the huge traffic from the broadband access networks, the transmission capacities of core networks are being dramatically accelerated with the use of timedivision multiplexing (TDM) and wavelength-division multiplexing (WDM) technologies; so that the total transmission capacity of WDM can reach up to 3 Tbps ( $40 \mathrm{Gbps}$ x 80 wavelengths). Recent investigation of digital coherent technologies enables the multilevel demodulation, polarization division multiplexing, and compensation of fiber dispersion with digital signal processing, so as to increase the spectral efficiency and transmission capacity up to 64 Tbit/s (107Gbps x 640 wavelength) in C and L band of $8 \mathrm{THz}$ [1].

As for the wireless access, the transmission speeds have also increased more than $100 \mathrm{Mbps}$ with wireless LAN (IEEE 802.11n), and accelerated up to $100 \mathrm{Mbps}$ mobile access with the Long Term Evolution (LTE). Japanese mobile operator started the LTE service at the end of 2010. We have been challenging the broadband mobile access beyond 100 Mbps with the 4G (LTE Advanced) mobile standardization.

The further enhancement of optical access technologies beyond 10G-EPON is facing various barriers to cost-effective realization: the history of the core network has proven this. In addition, a higher-speed TDMA requires higher-rate burst-mode circuits. Given this, one of the most attractive candidates for future optical access is WDM-PON, in which each signal from/to each user occupies a different wavelength. WDM-PON is a physically shared system, but a logically unshared system. This provides certain advantages as follows [2].

1. The bandwidth for each user can be easily upgraded.

2. Various services can be provided per wavelength.

*iwatuki.katumi@lab.ntt.co.jp; phone 81422 59-3197; fax 81422 60-7855

Broadband Access Communication Technologies VI, edited by Benjamin Dingel, Raj Jain, Katsutoshi Tsukamoto, Proc. of SPIE Vol. 8282, 828202 - @ 2012 SPIE · CCC code: 0277-786X/12/\$18 - doi: 10.1117/12.907499 


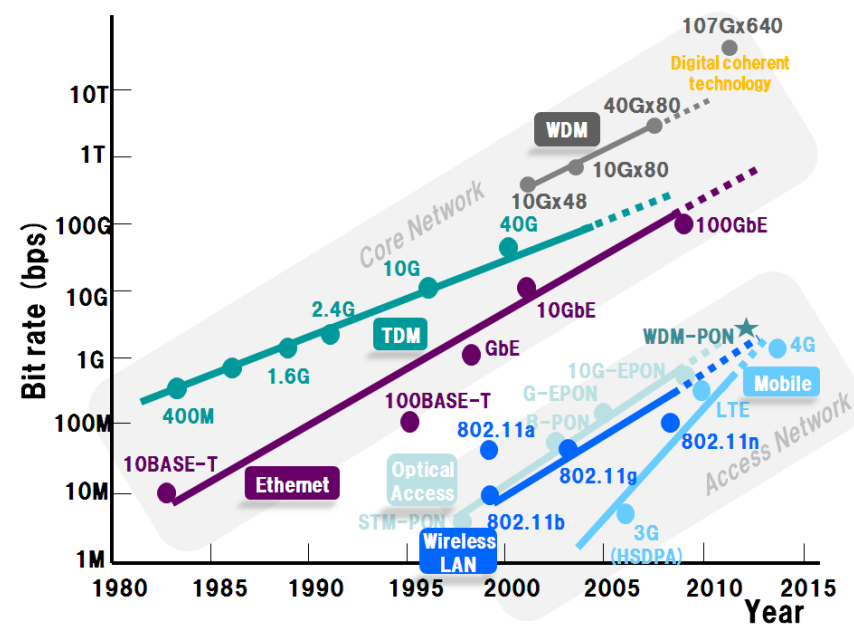

Figure 1. Transmission speeds of core and access networks.

From the viewpoint of advantage 2, the integration and convergence with wired and wireless broadband access over WDM-PON will flexibly provide ultra-high definition videos, 3D video, and rich Web applications with smart phones and tablet personal computers anywhere, at any time by easily connecting to cloud computing, as shown in Fig. 2. The cloud computing also provides information processing form a huge number of sensors with ubiquitous wireless sensor networks. Recent proposals establish to provide wireless and/or wired services over WDM-PON [2]-[5]. One of the most attractive approaches to easily and transparently transmitting RF signals over a wavelength is radio over fiber (RoF) techniques, so that various types of broadband wireless services in smaller radio cells can be flexibly and costeffectively accommodated with many base stations (BS) over WDM-PON [6]. The smaller radio cell increases the efficiency of frequency utilization, that gives the advantage in extremely restricted radio spectrum resources. The conventional RoF based on subcarrier modulation (SCM), however, is so-called analog optical transmission scheme, and therefore the characteristics of optoelectronics components and optical fibers greatly impact the transmission performance.

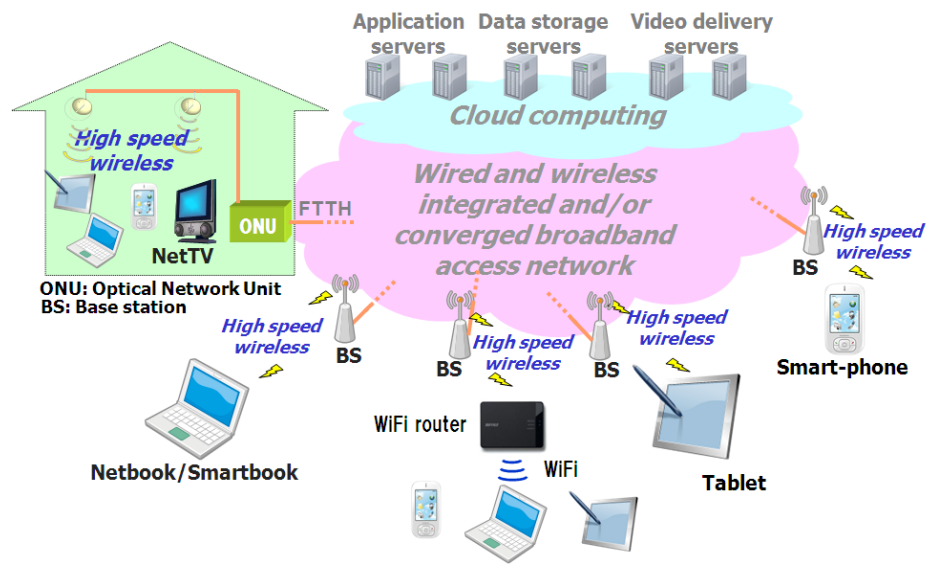

Figure 2. Wired and wireless integrated and/or converged broadband access network.

This paper reviews the technical issues of conventional RoF, their countermeasures, and RoF access networks using optical coherent technologies. Section 2 briefly describes the technical issues of conventional RoF based on SCM and their countermeasures. In Section 3, we show two examples of RoF access networks using optical coherent technologies 
to solve the technical issues; a video distribution system with FM conversion and wired and wireless integrated widearea access network with photonic up- and down-conversion.

\section{TECHNICAL ISSUES OF ROF AND COUNTERMEASURES}

The technical issues of conventional RoF based on SCM are as follows.

1. Intermodulation distortion due to nonlinear characteristics of optical devices [7]

2. Clipping noise due to direct modulation of laser diodes (LD) [8]

3. Degradation of optical reflection induced at mechanical splice points [9]

4. Distortion of RF signal due to fiber dispersion [10]

Table 1 summarizes the countermeasures with devising transmitters (Tx) and receivers (Rx) of RoF system. The technique 1 in Table 1 greatly reduces the above technical issues by introducing the digital signal processing. However, the timing jitter of digital analog converter (DAC) restricts the system performance of digitized RoF (DRoF) [11]. The other techniques in Table 1 mitigate the impact due to the technical issues by introducing the optical coherent technologies. The technique 2 reduces the impact due to the technical issues 1, 2, and 3 with FM modulation of LD and heterodyning detection, which converts multicarrier AM signals to FM signals [9]. This technique can be applied to OFDM RF signals to reduce the intermodulation distortion, clipping noise, and impact of optical reflection, as well. The techniques from 3 to 7 solves the technical issue 4 on the millimeter RF signal transmission, with the use of optically beating-up and -down the RF carrier frequency [12], [13], the single sideband (SSB) or carrier suppress (CS) modulation [14], [15], optically filtering the SSB at the detector [16], generating many harmonics by FM modulation of LD [17][18], and detecting the SSB with digital coherent detection [19], respectively. In the next section, we will describe the RoF access networks to apply the techniques 2 and 3 in Table 1 .

\begin{tabular}{|c|c|c|c|c|}
\hline & Techniques & Ref. & Tx & $\mathbf{R x}$ \\
\hline 1 & Digitized RoF & 11 & ADC + IM mod. & Direct detection + DAC \\
\hline 2 & FM conversion & 9 & $\begin{array}{l}\mathrm{FM} \text { and/or PM mod. and } \\
\text { heterodyning detection + IM } \\
\text { mod. }\end{array}$ & $\begin{array}{l}\text { Direct detection + self } \\
\text { delayed detection. }\end{array}$ \\
\hline 3 & $\begin{array}{l}\text { Photonic up- \& } \\
\text { down-conversion }\end{array}$ & 12,13 & $\begin{array}{l}\text { Photonic down-conversion + } \\
\text { IM mod. }\end{array}$ & $\begin{array}{l}\text { Photonic up-conversion + } \\
\text { heterodyning detection }\end{array}$ \\
\hline 4 & $\begin{array}{l}\text { SSB or CS } \\
\text { modulation }\end{array}$ & 14,15 & SSB or CS mod. & Heterodyning detection \\
\hline 5 & Optical filtering & 16 & IM mod. & $\begin{array}{l}\text { Optical bandpass filter + } \\
\text { direct detection }\end{array}$ \\
\hline 6 & $\begin{array}{l}\text { Optical frequency } \\
\text { multiplying }\end{array}$ & 17,18 & $\begin{array}{l}\text { FM modulation + IM mod. + } \\
\text { MZI }\end{array}$ & $\begin{array}{l}\text { Direct detection + bandpass } \\
\text { filter }\end{array}$ \\
\hline 7 & $\begin{array}{l}\text { Digital coherent } \\
\text { detection }\end{array}$ & 19 & PM mod. & Digital coherent detection \\
\hline
\end{tabular}

Table 1. Countermeasures based on techniques of transmitters (Tx) and receivers (Rx).

\section{COHERENT ROF ACCESS NETWORKS}

\subsection{Video distribution system with FM conversion}

Figure 3 shows the commercially deployed FTTH system configuration. The GE-PON system (IEEE 802.3ah) consists of GE-OLT and GE-ONU, and provides voice and data communication services [9]. In the video distribution system, multichannel video signals from the head-end are E/O converted in the transmitter and relayed by V-OLTs. After transmitting the access network, the GE-PON signal and video signal is terminated in the GE-ONU and V-ONU, respectively. The wavelength allocation is, in compliance with recommendation ITU-T G.983.3, $1.49 \mu \mathrm{m}$ and $1.31 \mu \mathrm{m}$ for downstream and upstream, respectively, in the GE-PON system, and $1.55 \mu \mathrm{m}$ in the SCM-PON system. 


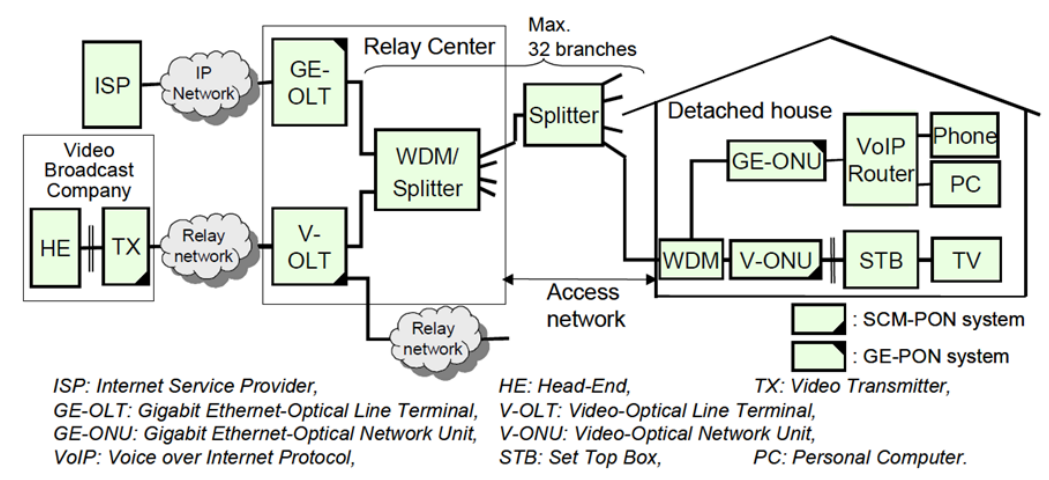

Figure 3. FTTH system configuration.

Figure 4 (a) and (b) show the configurations of video distribution system with the FM conversion system [9] and the conventional SCM, respectively. The difference between two systems is that the FM conversion system has an FM converter in the video transmitter and an FM demodulator in the V-ONU. In the FM converter, the multichannel FDM video signal is split into two signals with $180^{\circ}$ phase difference, and each signal modulates the optical frequency of a different FM LD. This modulation scheme reduces not only the FM modulation current but also the intensity modulation component generated by FM modulation. Optical heterodyne detection generated the broadband FM signal with center frequency of $3 \mathrm{GHz}$. The sharing of the expensive optical coherent process among the subscribers minimizes the cost per subscriber. The FM demodulator in the ONU is also shown in Fig. 4 (a). An exclusive OR gate detects both riseand fall-edge of the FM signal to improve CNR characteristics.

The FM conversion technique offers the following benefits over conventional SCM systems: (1) Improved minimum received optical power, by around $5 \mathrm{~dB}$ for $\mathrm{AM}$ video transmission, (2) RIN requirement eased by around $10 \mathrm{~dB}$ to $135 \mathrm{~dB} / \mathrm{Hz}$, which allows more than 20 optical amplifiers to be cascaded, (3) Reflectivity of the optical connector eased by $10 \mathrm{~dB}$, (4) WDM filter crosstalk requirement eased by $14 \mathrm{~dB}$ and influence of non-linear crosstalk caused by Raman scattering rendered insignificant.

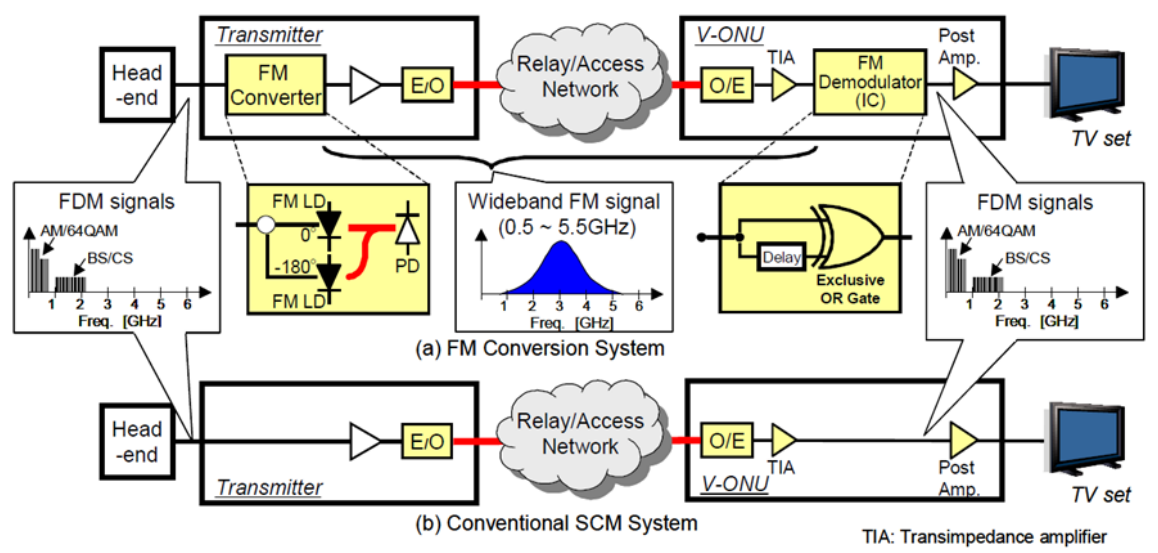

Figure 4. Configuration of video distribution system. (a) FM conversion system, (b) Conventional SCM system.

\subsection{Wired and wireless integrated wide-area access network with photonic up- and down-conversion}

Figure 5 illustrates the wired and wireless wide-area access network based on long-reach WDM-PON [13]. OLTs and an optical carrier supply module (OCSM) are located in the center node; the OCSM is an optical frequency comb generator that supplies multi-wavelength carriers to several OLTs. The OLT has interfaces for RoF access (RoF IFs) as well as those for high speed optical access such as 10 Gigabit Ethernet (10GE IFs). The RoF approach simplifies the system architecture by directly delivering broadband RF signals through optical fibers. 


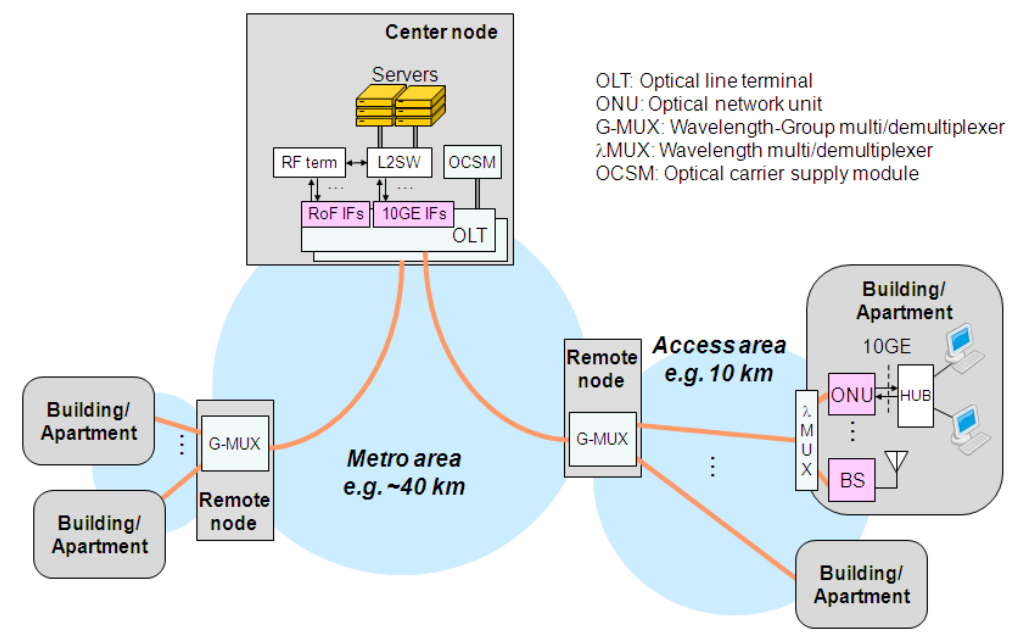

Figure 5. Wired and wireless integrated wide-area access network.

One of the most attractive RoF approaches over $100 \mathrm{Mbps}$ with the millimeter band is photonic up- and downconversion heterodyning two optical frequencies whose difference corresponds to the RF, e.g. $60 \mathrm{GHz}[20]$. By modulating one of two optical frequencies before fiber transmission, the RF signal can be extracted by heterodyne detection after fiber transmission. This approach can eliminate not only the local RF generator in each base station (BS), but also reducing the fading of RF signals due to the fiber dispersion. In order to generate a stable RF signal after detection, the precisely controlled optical frequencies must be required. The OCSM that can inherently provide such precise frequency control between any two wavelengths are an attractive candidate for this purpose as well as for multiplexing many different RF signals.

This network uses DWDM wavelength channels (e.g. 64 channels) and the group multi/demultiplexer (G-MUX) in each remote node divides/combines the DWDM channels into/from several groups of wavelengths (e.g. 8 wavelengths $\mathrm{x} 8$ groups). Each wavelength group is dedicated to a building/apartment, where a wavelength pair can provide either optical access via an ONU or RoF access with a BS (e.g. 1 x 10GE-ONU and 3 x RoF BSs in each building/apartment).

Figures 6 (a) and (b) show the configuration and optical spectrum of the OCSM [21]. By modulating the CW lights of seed laser diodes (LDs $\lambda_{1}$ to $\lambda_{n}$ in the figure) with a phase modulator (PM) and an intensity modulator (IM) using 25 $\mathrm{GHz}$ radio frequencies with appropriate amplitudes, we can obtain multi-wavelength optical carriers as the modulation sideband as shown in Fig. 6 (b); the spectrum consists of four wavelength groups where each group consists of eight wavelengths with $25 \mathrm{GHz}$ spacing. Typically, low-cost optical filters for group multi/demultiplexing require an adequate guard-band between neighboring groups. As shown in the spectrum, this OCSM is very suitable for such a group multi/demultiplexing because one can easily adjust the spacing between neighboring wavelength groups by adjusting the seed wavelengths.

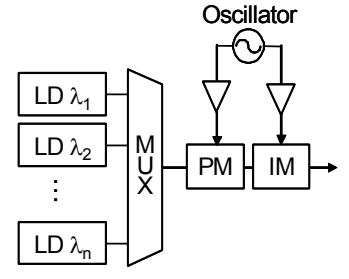
LD: Laser Diode, MUX: Wavelength Multiplexer
PM: Phase Modulator, IM: Intensity Modulator

(a)

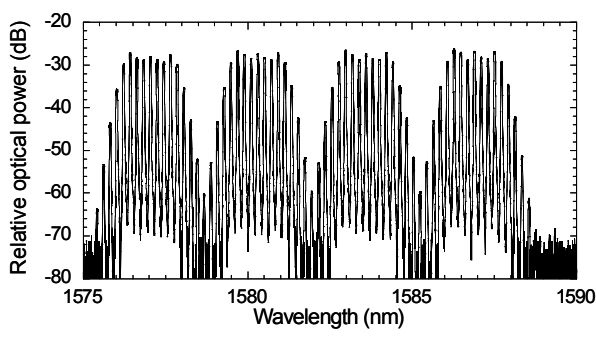

(b)

Figure 6. (a) Configuration and (b) optical spectrum of optical carrier supply module (OCSM).

Figure 7 shows a detailed configuration of the proposed network system. Wavelength pairs to be used for an ONU or a BS are $\lambda_{\mathrm{k} 1} / \lambda_{\mathrm{k} 3}, \lambda_{\mathrm{k} 2} / \lambda_{\mathrm{k} 4}, \lambda_{\mathrm{k} 5} / \lambda_{\mathrm{k} 7}, \lambda_{\mathrm{k} 6} / \lambda_{\mathrm{k} 8}$ where $\mathrm{k}$ is the group number $(\mathrm{k}=1 \sim \mathrm{n})$. In the case of the OCSM shown in Fig. 7 (b), $\mathrm{n}$ is 4; we can increase $\mathrm{n}$ by adding seed wavelengths to OCSM. The center node consists of $\mathrm{n}$ sets of modulation 
arrays (Mod array), $\mathrm{n}$ sets of receiver arrays (Rec array) and group multi/demultiplexers (G-MUX/G-DMX). Each Mod array multi/demultiplexes the eight wavelengths in each group by using arrayed-waveguide gratings (AWGs), and $\lambda_{\mathrm{k} 1}$, $\lambda_{\mathrm{k} 2}, \lambda_{\mathrm{k} 5}, \lambda_{\mathrm{k} 6}$ are modulated by $10 \mathrm{Gbit} / \mathrm{s}$ binary NRZ data (for optical access) or $10 \mathrm{GHz}-$ band IF data (for RoF access). In the remote node, the G-MUX/DMX divides/combines signals by wavelength groups. In the building, AWGs multi/demultiplex the eight wavelengths. The BS receives the RoF signal by heterodyning the wavelength pair (e.g. $\left.\lambda_{\mathrm{k} 1} / \lambda_{\mathrm{k} 3}\right)$ to generate a wireless signal with $60 \mathrm{GHz} \mathrm{RF}$ as well as transmitting the RoF signal by remotely modulating and transmitting one of the wavelength pairs (e.g. $\lambda_{\mathrm{k} 3}$ ) upstream. The ONU simply receives one modulated wavelength pair (e.g. $\lambda_{\mathrm{k} 2}$ ) as well as modulating/demodulating another wavelength pair (e.g. $\left.\lambda_{\mathrm{k} 4}\right)$. Figure 8 summaries the signal spectra of OLT, ONU, and OLT. By using this system configuration, we can realize a wide-area access network that provides both high-speed optical access and fiber-wireless access flexibly depending on need.

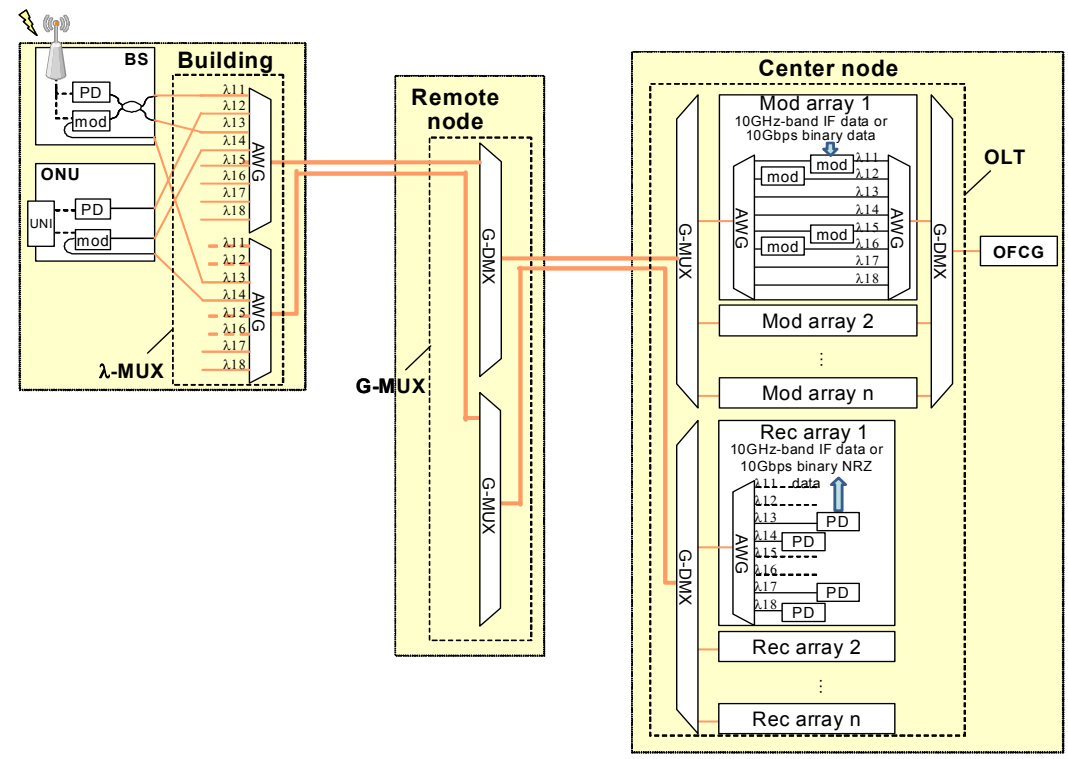

Figure 7. System configuration of wired and wireless integrated wide-area access network.

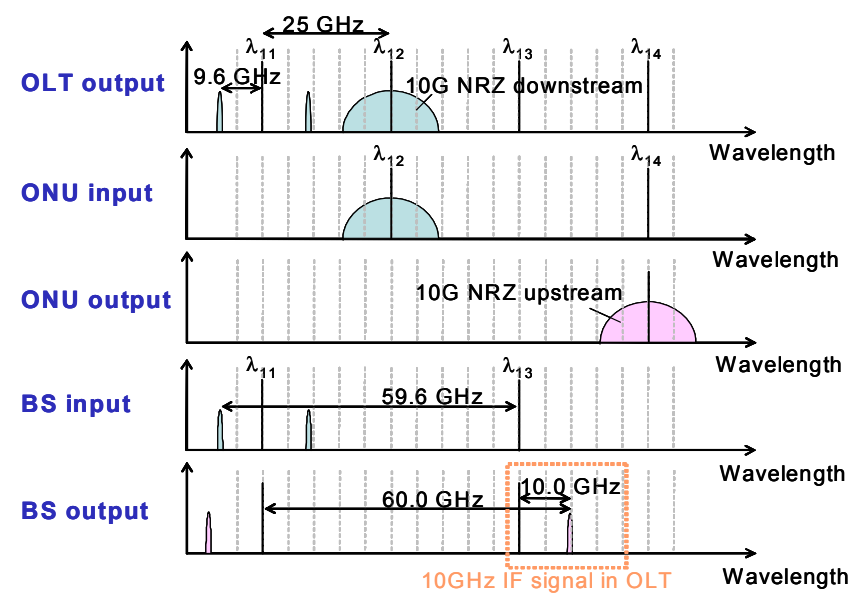

Figure 8. Signal spectra of OLT, ONU and BS.

\section{SUMMARY}

We have described the technical issues of conventional RoF based on SCM, their countermeasures, and RoF access networks using optical coherent technologies to solve the technical issues. To apply the optical coherent technologies to $\mathrm{RoF}$, the impact of characteristics in optoelectronics components and optical fibers can be greatly reduced. We described the two examples of broadband RoF access networks; a video distribution system with FM conversion and 
wired and wireless integrated wide-area access network with photonic up- and down-conversion. The former technique can greatly improve the transmission performance on multicarrier RF signals, e.g. OFDM signals. The latter technique enables broadband optical digital transmission and millimeter RF signals transmission simultaneously over long-reach WDM-PON.

\section{ACKNOWLEDGEMENT}

The author is grateful thanks to Drs. Hisao. Yoshinaga of NTT Access Network Service Systems Laboratories for his fruitful discussions.

\section{REFERENCES AND LINKS}

1. X. Zhou, J. Yu, M. Huang, Y. Shao, T. Wang, L. Nelson, P. Magill, M. Birk, P. I. Borel, D. W. Peckham, R. Lingle, Jr., and B. Zhu, "64-Tb/s, 8 b/s/Hz, PDM-36QAM transmission over $320 \mathrm{~km}$ using both pre- and posttransmission digital signal processing", IEEE J. Lighwave Technol., Vol. 29, No. 4, pp.571-577 (2011)

2. K. Iwatsuki, and J. Kani, "Applications and technical issues of wavelength-division multiplexing passive optical networks with colorless ONUs", J. Optical Communications and Networking Vol.1, No.4 pp.C17-C24 (2009)

3. K. Tsukamoto, T. Nishiumi, T. Yamakami, T. Higashino, S. Komaki, R. Kubo, T. Taniguchi, J. Kani, N. Yoshimoto, H. Kimura, and K. Iwatsuki, "Convergence of WDM access and ubiquitous antenna architecture for broadband wireless services", PIERS Online, Vol. 6, No. 4, pp.385-389 (2010)

4. K. Prince, J. B. Jensen, A. Caballero, X. Yu, T. B. Gibbon, D. Zibar, N. Guerrero, A. V. Osadchiy, and I. T. Monroy, "Converged wireline and wireless access over a 78-km deployed fiber long-reach WDM-PON", IEEE Photonics Technol. Lett., Vol.21, No.17, pp.1274-1276 (2009)

5. W-T. Shaw, S-W. Wong, S-H. Yen, and L. G. Kazovsky, "An Ultra-scalable broadband architecture for municipal hybrid wireless access using optical grid network", OFC/NFOEC2009, OThP2 (2009)

6. K. Iwatsuki, T. Taniguchi, T. Tashiro, K. Hara, J. Kani, N. Yoshimoto, H. Kimura, K. Tsukamoto, T. Higashino, and S. Komaki, "Broadband ubiquitous femto-cell network with MIMO distributed antenna system over WDMPON", Proceedings of SPIE Vol.7958, Paper 7958-16 (2011)

7. T. Kurniawan, A. Nirmalathas, C. Lim, D. Novak, and R. Waterhouse, "Performance analysis of optimized millimeter-wave fiber radio links," IEEE Trans. Microwave Theory Tech., vol. 54, no. 2, pp.921-928 (2006)

8. S. S. Wagner, T. E. Chapuran, and R. C. Menendez, "The effect of analog video modulation on laser clipping noise in optical video-distribution networks", IEEE J. Lightwave Technol., vol. 8, pp.275-277 (1996)

9. H. Yoshinaga and N. Shibata, "Commercially deployed coherent system for video distribution", IEEE/LEOS Summer Topical Meeting on Coherent Optical Communication Systems, TuC1.2 (2008)

10. H. Schmuck, "Comparison of optical millimetre-wave system concepts with regard to chromatic dispersion", Electron.Lett., Vol.31 pp.1848-1849 (1995)

11. A. Nirmalathas, P. A. Gamage, C. Lim, D. Novak, R. Waterhouse, and Y. Yang, "Digitized RF transmission over fibers", IEEE Microwave Magazine, June, pp.75-81, (2009)

12. H. Toda, T. Nakasyotani2, T. Kuri, and K. Kitayama, "A full-duplex WDM millimeter-wave-band radio-on-fiber system using a supercontinuum light source", MWP2005, pp.111-114 (2005)

13. J. Kani, "Trends in next generation optical access networks and a proposed hybrid optical/wireless wide-area access network", Progress In Electromagnetics Research Symposium (PIERS) 2008, pp.421-425 (2008)

14. Z. Jia, J. Yu, G. Ellinas, and G. K. Chang, "Key enabling technologies for optical-wireless networks: optical millimeter-wave generation, wavelength reuse, and architecture", IEEE J. Lightwave Technol., vol. 25, pp.3452$3471(2007)$

15. C.-T. Lin, J. Chen, P.-T. Shih, W. Jr Jiang, and S. Chi, "Ultra-high data-rate $60 \mathrm{GHz}$ radio-over-fiber systems employing optical frequency multiplication and OFDM formats", IEEE J. Lightwave Technol., vol. 28, pp.2296$3471(2010)$

16. J. Yu, J. Hu, D. Qian, Z. Jia, G. K. Chang, and T. Wang, "Transmission of microwave-photonics generated 16Gbit/s super broadband OFDM signals in radio-over-fiber system", OFC/NFOEC2008, OThP2 (2008)

17. A.M.J. Koonen, M. Garcia Larrode, A. Ng'oma, K. Wang, H. Yang, Y. Zheng, E. Tangdionggam, "Perspectives of radio over fiber technologies", OFC/NFOEC2008, OThP3 (2008) 
18. A. Murakoshi, K. Tsukamoto, and S. Komaki :"High-performance RF signals transmission in SCM/WDMA radioon-fiber bus link using optical FM method in presence of optical beat interference", IEEE Transactions on Microwave Theory and Techniques, Vol.54, pp.967-972, (2006)

19. A. Caballero, D. Zibar, I. T. Monroy, "Digital coherent detection of multi-gigabit 40 GHz carrier frequency radioover-fibre signals using photonic downconversion”, Electron. Lett., Vol. 46 pp.57-58 (2010)

20. T. Taniguchi, N. Sakurai, K. Kumozaki, and T. Imai, "Loop-back Optical Heterodyne Technique for 1.0-Gb/s Data Transmission Over 60-GHz Radio-On-Fiber Uplink,” IEEE J. Lightwave Technol., vol. 25, pp.1484-1494 (2007)

21. M. Fujiwara, M. Teshima, J. Kani, H. Suzuki, N. Takachio, and K. Iwatsuki, “Optical carrier supply module using flattened optical multicarrier generation based on sinusoidal amplitude and phase hybrid modulation", IEEE. J. Lightwave Technol., Vol.21, No.11, pp.2705-2714 (2003) 